\title{
The pattern of ocular emergencies in Lumbini Eye Institute and Research Center
}

\author{
Kabindra Bajracharya1, Bimala Bajracharya ${ }^{2}$, Anjita Hirachan ${ }^{3}$, Kriti Joshi ${ }^{4}$ \\ ${ }^{1}$ Associate Professor and Consultant Pediatric Ophthalmologist, ${ }^{2}$ Nursing Consultant, ${ }^{3}$ Assistant Professor and \\ Pediatric Ophthalmologist, ${ }^{4}$ Fellow Pediatric Ophthalmology and Strabismus, Lumbini Eye Institute and Research \\ Center, Bhairahawa, Nepal
}

Background: An ocular emergency is any condition in which early action is necessary to prevent severe and permanent damage to the eye. Aims and Objective: To describe the pattern of common ocular diseases presenting in emergency department. Materials and Methods: This was descriptive retrospective study conducted for the period of six months from 1st March 2019 to 31 August 2019, in emergency department of Lumbini Eye Institute and Research Center, Bhairahawa, Nepal. The data were documented from medical records in terms of age, sex, presenting visual acuity in affected eye, address and diagnosis of the disease. Results: There were total 604 patients who visited in six months period, 439 male $(72.68 \%), 165$ female $(27.32 \%)$ with male to female ratio of 2.66. The patients from Lumbini Zone were $490(81.1 \%)$, out of Lumbini Zone, Nepal were $40(6.6 \%)$ and $74(12.3 \%)$ were from India. There were $182(30.1 \%)$ patients below 16 years of age. The largest number of patients were between 21-40 years comprising $41.9 \%$. The common ocular emergencies were foreign body $(13.1 \%)$, blunt trauma $(11.9 \%)$, conjunctivitis $(10.4 \%)$, open globe injury $(10.3 \%)$ and corneal epithelial defect $(9.3 \%)$. Conclusion: Most of the patients in emergency were male. The middle age patients were common followed by pediatric age group. Trauma and conjunctivitis were the most common ocular emergencies.

Key words: Ocular emergency; Trauma; Conjunctivitis

\section{Access this article online}

Website:

http://nepjol.info/index.php/AJMS DOI: 10.3126/ajms.v12i7.35373

E-ISSN: 2091-0576

P-ISSN: $2467-9100$

Copyright (c) 2021 Asian Journal of Medical Sciences

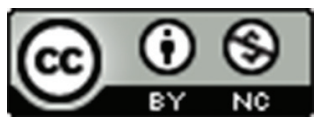

This work is licensed under a Creative Commons Attribution-NonCommercial 4.0 International License.

\section{INTRODUCTION}

Lumbini Eye Institute and Research Center is one of the tertiary eye hospitals of Nepal with the care for emergency eye diseases and general anesthesia facility. The patients with eye diseases from Western part of Nepal and Uttar Pradesh of India visit this hospital as referral center.

An ocular emergency can be defined as any condition in which early action is necessary to prevent severe to permanent damage to the eye. ${ }^{1}$ Ocular emergency can be as minor as foreign body for e.g. eyelash inside the eye to the vision threatening conditions e.g. chemical injuries. Ocular trauma is recognised as the leading cause of unilateral blindness. ${ }^{2}$ Ocular emergency needs immediate examination and prompt treatment as some of the conditions may cause permanent vision loss and the visual outcome may depend on timely management. ${ }^{3}$ Ocular trauma and ocular infections are common ocular emergencies. ${ }^{4} \mathrm{~A}$ total number of 127 children visited with Penetrating eye injuries who needed surgical intervention in a year in the hospital where this study was conducted. ${ }^{5}$

Chemical injury needs immediate irrigation of eyes even before visual acuity assessment. Normal saline or Ringer lactate solution can be used, sometimes clean water has to be used if no other option available to wash the chemicals from eyes before it damages eye. ${ }^{3}$

Open globe injury needs surgical intervention as soon as possible to prevent endophthalmitis. In case of children, 
the patient should be given nothing by mouth taking in account for need of general anesthesia for surgery. Eye shield should be applied to prevent further damage and topical medication is to be avoided.

The aim of this study was to describe the common ocular diseases presented in emergency department.

\section{MATERIALS AND METHODS}

This study was descriptive retrospective conducted for the period of six months from 1st March 2019 to 31st August 2019. The approval was taken from Institutional Review Committee of the hospital.

All of the patients who visited emergency department of Lumbini Eye Institute and Research Center during study period were included in this study. The data were collected from medical records in terms of age, sex, address, visual acuity at presentation in affected eye, and diagnosis of the disease. The data were entered in SPSS version 20 and variables were analyzed as frequency and percentages.

\section{RESULTS}

In this study, there were total 604 patients who visited emergency department during six months period. Male patients were $439(72.68 \%)$ and female were $165(27.32 \%)$ with male to female ratio of 2.66 . The patients from Lumbini zone were 490 (81.1\%), out of Lumbini, Nepal were $40(6.6 \%)$ and $74(12.3 \%)$ were from India. There were $182(30.1 \%)$ patients below 16 years of old. The largest number of patients were between 21-40 years of age comprising $41.9 \%$. The second most common age group was below 10 years (21.2\%) (Table 1). Approval was obtained from the Institutional Ethics Committee prior to the commencement of the study.

The common ocular emergencies were foreign body $(13.1 \%)$, blunt trauma $(11.9 \%)$, conjunctivitis $(10.4 \%)$, open globe injury $(10.3 \%)$ and corneal epithelial defect $(9.3 \%)$ (Table 2).

Ocular infection was also common cause for emergency visits. The ocular infections were conjunctivitis, corneal ulcer, preseptal cellulitis, orbital cellulitis and endophthalmitis accounting $15 \%$ of the total emergency cases (Table 2).

The trauma related corneal foreign body (hanging nail penetrating cornea) while hammering nail on the wall (Figure 1) and full thickness corneal laceration with traumatic cataract has been shown in the Figure 2.

\begin{tabular}{|c|c|c|c|}
\hline S. N. & Age & Frequency & Percent \\
\hline 1 & $0-10$ & 128 & 21.2 \\
\hline 2 & $11-16$ & 54 & 8.9 \\
\hline 3 & $17-20$ & 43 & 7.1 \\
\hline 4 & $21-30$ & 145 & 24 \\
\hline 5 & $31-40$ & 108 & 17.9 \\
\hline 6 & $41-50$ & 57 & 9.4 \\
\hline 7 & $51-60$ & 36 & 6 \\
\hline 8 & $61-70$ & 18 & 3 \\
\hline 9 & $71-80$ & 13 & 2.2 \\
\hline 10 & $81-90$ & 2 & 0.3 \\
\hline Total & & 604 & 100 \\
\hline
\end{tabular}

\begin{tabular}{|c|c|c|c|}
\hline S.N. & Diagnosis & Frequency & Percentage \\
\hline 1 & Extraocular Foreign body & 79 & 13.1 \\
\hline 2 & Blunt trauma & 72 & 11.9 \\
\hline 3 & Conjunctivitis & 63 & 10.4 \\
\hline 4 & Open globe injury & 62 & 10.3 \\
\hline 5 & Epithelial defect & 56 & 9.3 \\
\hline 6 & Toxic conjunctivitis & 36 & 6 \\
\hline 7 & $\begin{array}{l}\text { Subconjunctival } \\
\text { hemeorrhage }\end{array}$ & 31 & 5.1 \\
\hline 8 & Chemical injury & 29 & 4.8 \\
\hline 9 & Lid laceration & 23 & 3.8 \\
\hline 10 & Uveitis & 20 & 3.3 \\
\hline 11 & Conjunctival laceration & 18 & 3 \\
\hline 12 & Corneal ulcer & 16 & 2.6 \\
\hline 13 & Allergic Conjunctivitis & 15 & 2.5 \\
\hline 14 & Thermal injury & 12 & 2 \\
\hline 15 & Preseptal/Orbital Cellulitis & 9 & 1.5 \\
\hline 16 & Dry eye & 4 & 0.7 \\
\hline 17 & Endophthalmiltis & 3 & 0.5 \\
\hline 18 & Others & 56 & 9.3 \\
\hline Total & & 604 & 100 \\
\hline
\end{tabular}

\begin{tabular}{|c|c|c|c|}
\hline S.N. & Visual acuity & Frequency & Percentage \\
\hline 1 & $6 / 6-6 / 18$ & 361 & 59.8 \\
\hline 2 & $6 / 24-6 / 60$ & 60 & 9.9 \\
\hline 3 & $<6 / 60$ & 126 & 20.9 \\
\hline 4 & CSM & 44 & 7.3 \\
\hline 5 & Not available & 13 & 2.2 \\
\hline Total & & 604 & 100 \\
\hline
\end{tabular}

The unaided visual acuity at presentation on the affected eyes were 6/6-6/18 in 361 (59.8\%), 6/24-6/60 in 60 (9.9\%) and less than $6 / 60$ in 126 (20.9\%). In small children visual acuity couldn't be assessed but CSM was present in 44 $(7.3 \%)$ and was not documented in 13 (2.2\%) (Table 3).

\section{DISCUSSION}

In this study, male were predominant with $72.68 \%$ which was similar to study by Pandey $\mathrm{PR}^{4}$, Jan $\mathrm{S}$ et $\mathrm{al}^{6}$, Dulal S 


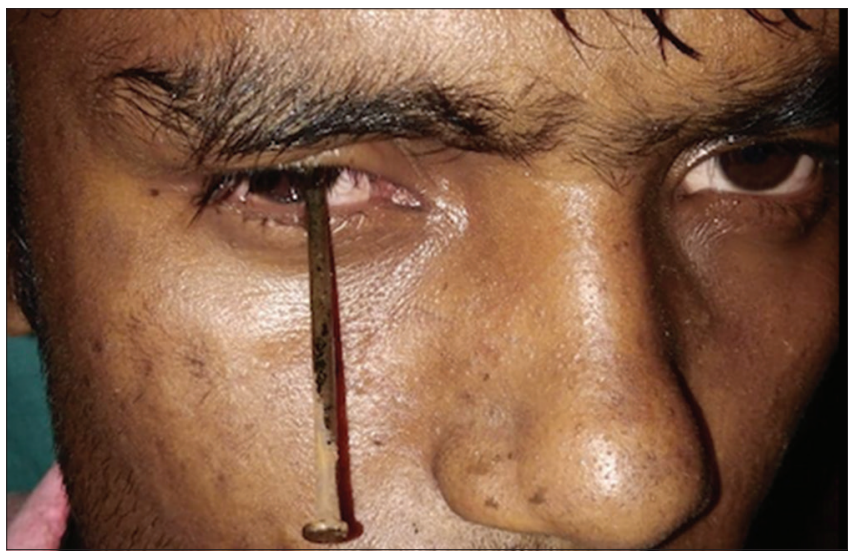

Figure1: Corneal foreign body (nail, penetrating cornea)

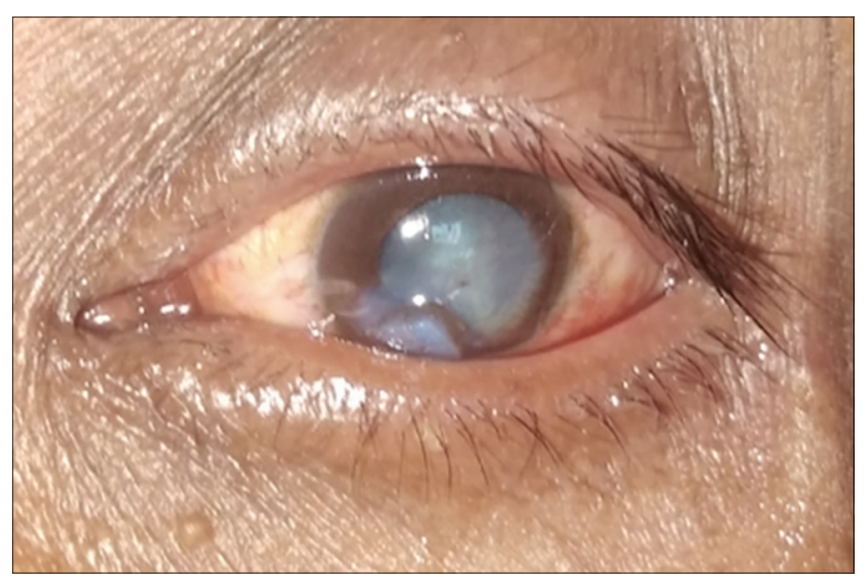

Figure 2: Full thickness corneal laceration with traumatic cataract

et $\mathrm{al}^{7}$, and Kinderan $\mathrm{YV}$ et $\mathrm{al}^{8}$ who found $73.6 \%, 66.67 \%$, $62 \%$ and $69.3 \%$ respectively. Trauma was common in male which might be due to aggressive nature.

In this study, 30.1\% patients were below 16 years of old which was similar to the study by Dulal S et $\mathrm{al}^{7}$ who found ocular trauma in $54.7 \%$ below 16 years. The maximum number of patients were between 21- 40 years of age comprising $41.9 \%$. The second most common age group was below 10 years (21.2\%) and $21 \%$ were above 40 years. It was similar to the study by Jan $\mathrm{S}$ et $\mathrm{al}^{6}$ who had most $(83.78 \%)$ of traumatic ocular emergencies below 40 years and $60.75 \%$ below 20 years of age and only $16.21 \%$ cases were 40 years and above. The reason behind the ocular emergency being common in below 40 years could be due to active age in outdoor work and therefore prone for trauma and infection.

Foreign body was most common presentation as in this study comprising $13.1 \%$ which was the commonest presentation (40\%) among trauma cases in the study by Pandey PR et al $1^{4}$. Injury is the cause for most the ocular emergency visit, open globe injury 10.3\%, blunt trauma $11.9 \%$, chemical injury $4.8 \%$ and thermal injury $2 \% ; 58.2 \%$ in total were due to injury. It was similar as in the study by Pandey et $\mathrm{al}^{4}$, where $75.7 \%$ were due to trauma.

Ocular infection was also common cause for emergency visit. The presentations were conjunctivitis, corneal ulcer, preseptal cellulitis, orbital cellulitis and endophthalmitis accounting $15 \%$ of the cases. Ocular infection was $24.3 \%$ in the study by Pandey et $\mathrm{al}^{4}$.

The visual acuity at presentation on the affected eyes were less than $6 / 60$ in $20.9 \%$ and not available in $2.2 \%$. The poor vision with ocular trauma needed admission and surgical intervention. One of the study by Kang Eugene $\mathrm{Yu}-\mathrm{Chuan} \mathrm{et}^{\mathrm{al}}{ }^{9}$ showed the presenting visual acuity can be one of the indicator of ocular emergency and need for intervention, admission and time for managing ocular emergency.

\section{CONCLUSION}

Most of the patients in emergency were male. The middle age patients were common followed by pediatric age group. Trauma and conjunctivitis were the most common ocular emergencies who presented in hospital. Early surgical intervention is necessary to prevent severe damage in case of open globe injury.

\section{REFERENCES}

1. Jones G. Management of Ocular Emergencies. Veterinary Nursing Journal. 1996; 11(1): 12-19.

https://doi.org/10.1080/17415349.1996.11012780

2. Cheung CA, Rogers-Martel M, Golas L, Chepurny A, Martel JB and Martel JR. Hospital-based ocular emergencies: epidemiology, treatment, and visual outcomes. Am J Emerg Med. 2014; 32(3):221-224.

https://doi.org/10.1016/j.ajem.2013.11.015

3. Pokhrel PK and Loftus SA. Ocular Emergencies. American Family Physician. 2007; 27(6): 829-836.

4. Pandey PR. Study of Ocular Emergencies in Nepal Eye Hospital. Postgraduate Medical Journal of NAMS. 2009; 9(2): 24-27.

5. Bajracharya K, Rai S, Bhari A, Thapa H, Hirachan A, Pandey S, et al. Penetrating eye injuries in pediatric population: An epidemiological study and visual outcome. Asian Journal of Medical Sciences. 2016; 7(4), 84-87. https://doi.org/10.3126/ajms.v7i4.14690

6. Jan S, Khan S, Khan MN, Iqbal A and Mohammad S. Ocular emergencies. J Coll of Physicians and Surg Pak. 2004;14(6):333336. DOI: 06.2004/jcpsp.333336.

7. Dulal S, Ale JB and Sapkota YD. Profile of pediatric ocular trauma in mid-western hilly region of Nepal. Nepal J Ophthalmol. 2012;4(1):134-137. 
https://doi.org/10.3126/nepjoph.v4i1.5865

8. Kinderan $\mathrm{YV}$, Shrestha E, Maharjan IM and Karmacharya S. Pattern of ocular trauma in the western region of Nepal. Nepal $\mathrm{J}$ Ophthalmol. 2012; 4(1):5-9.

https://doi.org/10.3126/nepjoph.v4i1.5843
9. Kang Eugene Yu-Chuan, Tai WC, Lin JY, Huang CJ, Yeh PH, et al. Eye-related Emergency Department Visits with Ophthalmology Consultation in Taiwan: Visual Acuity as an Indicator of Ocular Emergency. Scientific Reports. 2020; 10:982: 1-7.

https://doi.org/10.1038/s41598-020-57804-2

Author's contribution:

KB-Concept and design of the study, reviewed literature, preparation and revision of manuscript; BB- Collection of data and revision of manuscript; $\mathrm{AH}-$ Reviewed literature and revision of manuscript; KJ- Design and revision of manuscript.

Work Attributed to:

Lumbini Eye Institute and Research Center, Siddharthanagar-3, Bhairahawa, Nepal.

Orcid ID:

Dr Kabindra Bajracharya- (10) http://orcid.org/0000-0002-1742-9220

Bimala Bajracharya- (i) http://orcid.org/0000-0001-7156-5736

Dr Anjita Hirachan- (1) http://orcid.org/0000-0001-7316-0302

Dr Kriti Joshi- (1) http://orcid.org/0000-0001-8998-9852

Source of funding: None, Conflicts of interest: None. 